\title{
1,2,3-Triazole-strapped calix[4]pyrrole: a new membrane transporter for chloride $\dagger$
}

\author{
Matthew G. Fisher, ${ }^{a}$ Philip A. Gale, ${ }^{*}, a$ Jennifer R. Hiscock, ${ }^{a}$ Michael B. Hursthouse, ${ }^{a}$ Mark E. Light, ${ }^{a}$ \\ Franz P. Schmidtchen ${ }^{b}$ and Christine C. Tong ${ }^{a}$
}

\author{
${ }_{5}$ Receipt/Acceptance Data [DO NOT ALTER/DELETE THIS TEXT] \\ Publication data [DO NOT ALTER/DELETE THIS TEXT] \\ DOI: 10.1039/b000000x [DO NOT ALTER/DELETE THIS TEXT]
}

A new triazole strapped calix[4]pyrrole synthesised via 'click' chemistry shows high affinity for chloride and lipid bilayer ${ }_{10}$ chloride transport properties.

Calix[4]pyrroles such as meso-octamethylcalix[4]pyrrole $\mathbf{1}$ have been extensively studied as anion and ion-pair receptors over recent years. ${ }^{1}$ Subsequently 'strapped' calix[4]pyrroles, pioneered by Lee and Sessler, have been synthesised that contain a single linker 15 between distal meso-positions. These compounds have increased affinity for anions relative to the parent macrocycle. ${ }^{2}$ Recently there has been increased interest in $\mathrm{CH}$ hydrogen bond donors ${ }^{3}$ and in particular in the use of 1,2,3-triazoles formed via 'click' chemistry ${ }^{4}$ as hydrogen bond donor groups for anion complexation. ${ }^{5} \mathrm{We}$ 20 decided to use 'click' chemistry to introduce a triazole strap into a calix[4]pyrrole and measure the anion binding ${ }^{6}$ and transport properties $^{7}$ of the resulting hybrid pyrrole/triazole anion receptor $\mathbf{2}$ (Figure 1).
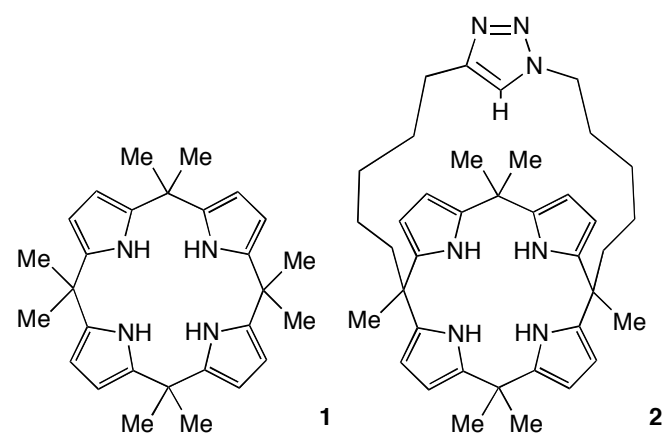

Fig. 1 Structure of meso-octamethylcalix[4]pyrrole 1 and strapped calix[4]pyrrole derivative 2 .

Full details of the synthesis of compound $\mathbf{2}$ are are provided in 30 the ESI. Single crystals of compound $\mathbf{2}$ were prepared by recrystallisation from methanol. I The structure (shown in Figure 2) reveals the calix[4]pyrrole adopting a 1,2-alternate conformation in which two methanol molecules are each bound to two pyrrole $\mathrm{NH}$ groups. Crystal structures of two DMSO solvates of compound ${ }_{35} \mathbf{2}$ have also been elucidated (see ESI).

\footnotetext{
${ }^{a}$ School of Chemistry, University of Southampton, Southampton, SO17 1BJ, UK. E-mail: philip.gale@soton.ac.uk; Fax: +44 (0)23 8059 6805; Tel: + 44 (0)238059 3332

${ }^{b}$ Department Chemie, Technische Universität München, 85747 Garching, Germany. E-mail: schmidtchen@ch.tum.de; Fax: +49 89-289-14698 $\dagger$ Electronic Supplementary Information (ESI) available: Synthesis and characterization data of new compounds, vesicle preparation and transport assays details. See http://dx.doi.org/10.1039/b000000x/
}
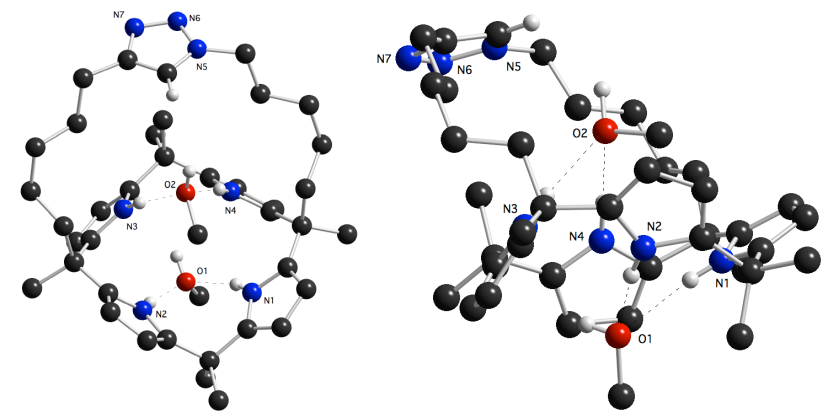

Fig. 2 Two views of the X-ray crystal structure of the methanol solvate of 1 showing the calixpyrrole macrocycle adopting the 1,2-alternate conformation.

40

The anion binding properties of compound 2 were studied by ${ }^{1} \mathrm{H}$ NMR titration techniques in acetonitrile- $d_{3}$ solution. Under these conditions addition of chloride resulted in slow exchange on the NMR timescale (Figure 3) with downfield shifts of the pyrrole $\mathrm{NH}$ 45 groups and triazole $\mathrm{CH}$ indicative of hydrogen bond formation. The slow exchange properties led us to study the anion binding properties of compound $\mathbf{2}$ by isothermal calorimetry.

In acetonitrile, the host-guest interaction of $\mathbf{2}$ and tetraethylammonium chloride appears as a clean, exothermic 1:1 50 stoichiometric binding process that is symmetric at millimolar concentrations (the result is independent of the sequence of addition of the binding partners; Figure 4). In comparison to the parent calixpyrrole 1 under the same conditions ${ }^{1 b}$ the enthalpy of complexation with $\mathbf{2}$ is substantially more negative as is expected 55 from the participation of an extra triazole-chloride hydrogen bond. However, this improved stickiness of $\mathbf{2}$ over $\mathbf{1}$ is again counteracted by an, on average, a slightly more negative entropy component resulting in an outcome that improves affinity due to the triazole strap by about an order of magnitude in $\mathrm{K}_{\mathrm{ass}}$ only.

${ }_{60}$ The strap also levels off the differences in complex stability depending on the solvent. Whilst in the case of the parent calixpyrrole 1 chloride binding in dichloromethane is weaker than in the more polar solvent acetonitrile because of an unfavorable complexation entropy overcompensating the more exothermic 65 enthalpy output there is almost an ideal balance of the enthalpic/entropic gains and losses in the strapped host $\mathbf{2}$ attesting to the less significant role of solvation in the latter case. Even under the most severe hydrogen bonding competition in methanol, 2 shows an exothermic response in chloride binding which, however, 70 did not suffice to derive an association constant. 


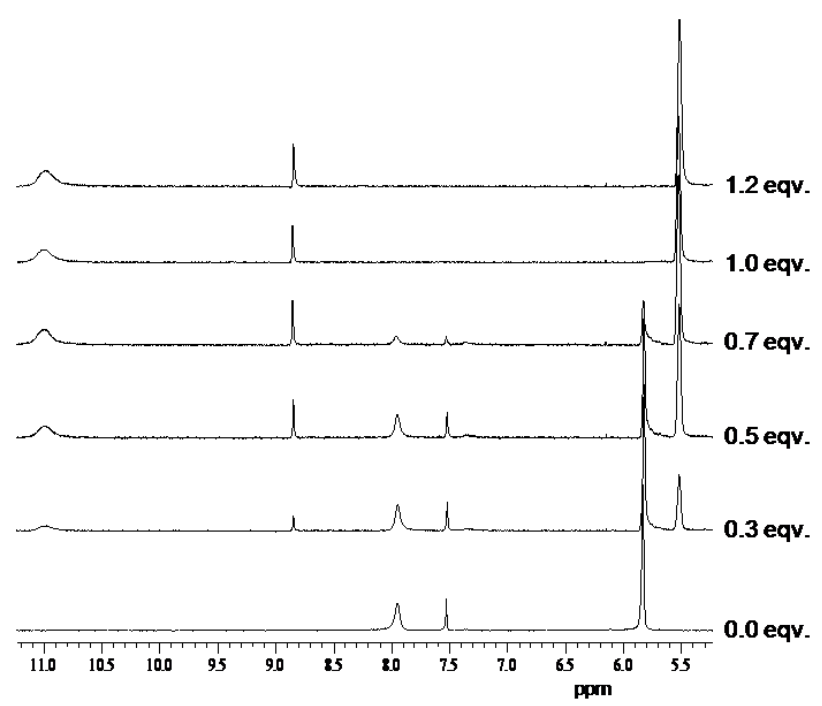

Figure 3 Partial ${ }^{1} \mathrm{H}$ NMR spectrum $(300 \mathrm{MHz})$ of compound 2 upon addition of tetrabutylammonium chloride in acetonitrile- $d_{3}$ solution at $298 \mathrm{~K}$.

75
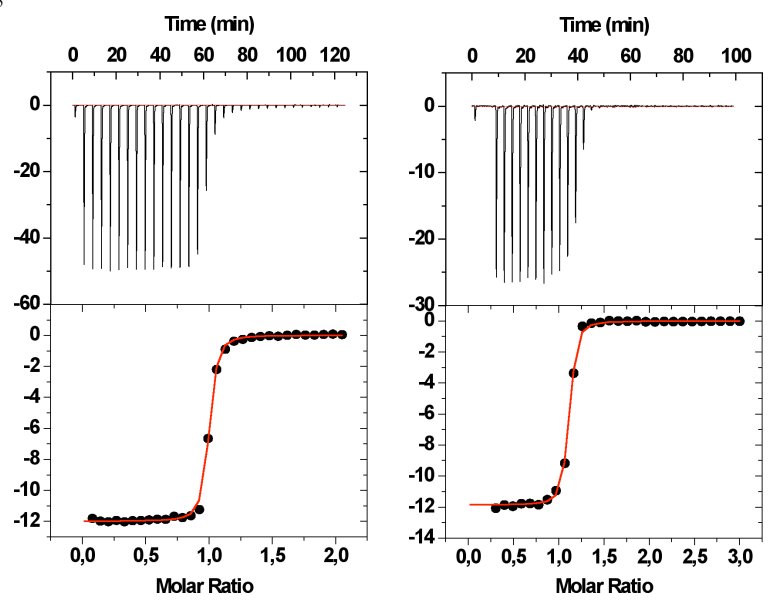

Figure 4 Isothermal calorimetric titration in acetonitrile at $303 \mathrm{~K}$ of tetraethylammonium chloride added into the solution of host $\mathbf{2}$ at 0.94 $80 \mathrm{mM}$ (left) or host $\mathbf{2}$ titrated into tetraetylammonium chloride solution at $0.327 \mathrm{mM}$ (right)

\section{[Please insert Table 1 at the bottom of this page - see below]}

${ }_{85}$ We have previously shown that compound $\mathbf{1}$ functions as a $\mathrm{CsCl}$ co-transporter across lipid bilayer membranes. ${ }^{8}$ However, this compound showed no transport activity for other group 1 metal chloride salts. The selectivity was attributed to the ability of the macrocycle to bind chloride to the NH hydrogen bonding array and ${ }_{90}$ caesium within the cavity formed by the pyrrole rings upon anion complexation. ${ }^{9}$ In order to study the transport properties of compound 2, we prepared separate samples of unilamellar 1palmitoyl-2-oleoylphophatidylcholine (POPC) vesicles loaded with $\mathrm{CsCl}, \mathrm{RbCl}, \mathrm{KCl}$ and $\mathrm{NaCl}$ and suspended them in an external ${ }_{95} \mathrm{NaNO}_{3}$ solution. A sample of calixpyrrole 2 ( $4 \%$ molar carrier to lipid) was added as a DMSO solution and the resultant $\mathrm{Cl}^{-}$efflux monitored using a chloride selective electrode. ${ }^{10}$ After five minutes the vesicles were lysed by addition of detergent and the final reading of the electrode used to calibrate $100 \%$ release of chloride.

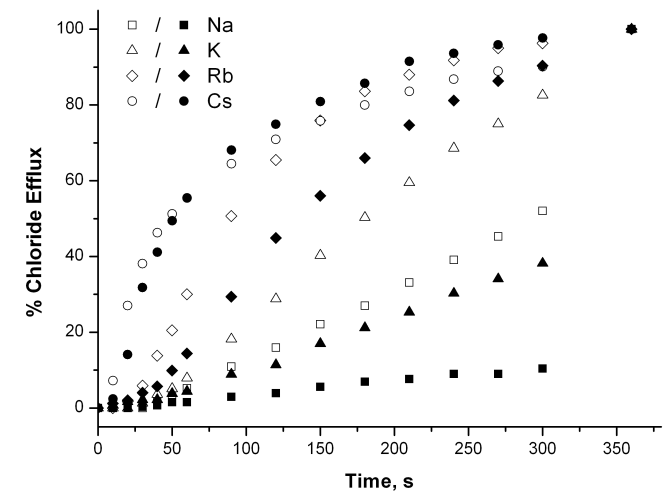

${ }^{100}$ Figure 5 Chloride efflux promoted by 2 at 0.04 molar equivalents of carrier to lipid, across unilamellar POPC vesicles loaded with $489 \mathrm{mM}$ $\mathrm{NaCl}(\square / \boldsymbol{\square}), \mathrm{KCl}(\triangle / \mathbf{\Delta}), \mathrm{RbCl}(\diamond / \diamond)$ and $\mathrm{CsCl}(\mathrm{O} / \bullet)$ buffered to $\mathrm{pH}$ 7.2 with $5 \mathrm{mM}$ phosphate dispersed in $489 \mathrm{mM} \mathrm{NaNO}_{3}$ (open symbols) or $105167 \mathrm{mM} \mathrm{Na} \mathrm{SO}_{4}$ (closed symbols) buffered to $\mathrm{pH} 7.2$ with $5 \mathrm{mM}$ phosphate.

The results show that compound 2 (Figure 5), in contrast to compound $\mathbf{1},{ }^{10}$ is capable of transporting chloride from sodium, 110 potassium and rubidium chloride containing vesicles with fastest release of the larger group 1 metal cation salts.

We wished to investigate the influence of the composition of the external media on the transport activity shown by $\mathbf{2}$. For this purpose group 1 metal chloride loaded vesicles were suspended in a $115 \mathrm{Na}_{2} \mathrm{SO}_{4}$ buffer. The results (Figure 5) show that carrier activity is essentially maintained although there is an increasing difference in the efficiency of transport as the metal ion size decreases. Sulfate is an extremely hydrophilic anion and is not normally possible to extract this anion from an aqueous phase into a lipid bilayer 120 membrane. In the case of the release of chloride mediated by compound 2 from caesium chloride containing vesicles there is little difference between the rate of chloride release as the exterior anion is changed from nitrate to sulfate. However, as the cation size decreases there is an increasing difference in rate of release 125 with, in the case of potassium and sodium, a considerably faster release of chloride from vesicles suspended in nitrate solution compared to those suspended in sulfate solution. This evidence leads us to suggest that both ion-pair co-transport and chloridenitrate antiport mechanisms are responsible for the release of ${ }_{130}$ chloride. As the cation size decreases, the transport mechanism changes from a predominantly ion-pair transport mechanism in the case of caesium chloride to a predominanty chloride - nitrate antiport process in the cases of sodium and potassium.

In order to provide evidence on the mechanism of the transport 135 process we performed transport assays using vesicles composed of a 70:30 mixture of POPC and cholesterol. The results shown in the Figure 6 clearly indicate a significant reduction of the transport activity of $\mathbf{2}$ when the vesicle bilayer composition includes cholesterol. Addition of cholesterol into the bilayer membrane ${ }_{40}$ significantly reduces its fluidity and this result is fully consistent with the process in question being governed by a carrier mechanism, rather than, for instance, channel formation. ${ }^{11}$ 


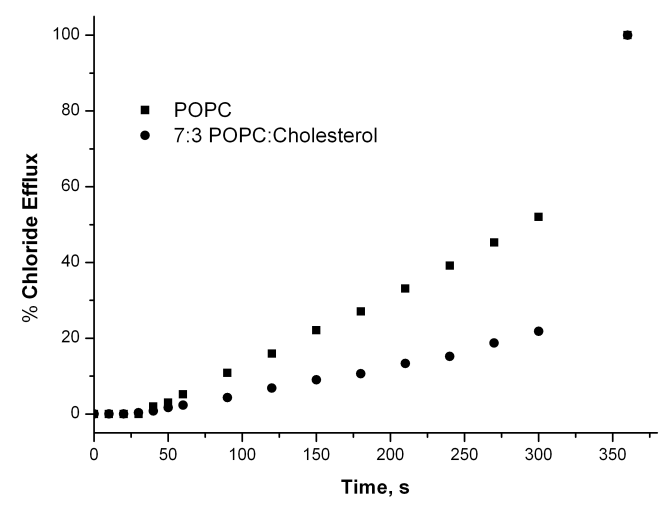

Figure 6 Chloride efflux promoted by 2, at 0.04 molar equivalents of 145 carrier to lipid, across unilamellar vesicles made of POPC (ם) or POPC with $30 \mathrm{~mol} \%$ of cholestrol $(\bullet)$ loaded with $489 \mathrm{mM} \mathrm{NaCl}$ buffered to $\mathrm{pH}$ $7.25 \mathrm{mM}$ phosphate buffer. The vesicles were dispersed in $489 \mathrm{mM}$ $\mathrm{NaNO}_{3}$.

${ }_{150}$ Strapped calix[4]pyrrole 2 functions as a chloride transporter in synthetic POPC and POPC/cholesterol vesicles. We propose that two mechanisms may be responsible for the release of chloride dependent upon the nature of the counter cation, namely ion-pair co-transport and chloride-nitrate antiport. This is in contrast to the

155 parent macrocycle $\mathbf{1}$ which functions as a caesium chloride cotransporter only. We are conducting studies to further probe anion transport mechanisms mediated by calix[4]pyrroles. The results of these studies will be reported in due course.

${ }_{160}$ P.A.G. thanks the EPSRC for a postdoctoral fellowship (CCT) and DTA studentships (MGF and JRH) and for access to the crystallographic facilities at the University of Southampton. P.A.G. thanks Dr. Roberto Quesada (Burgos) for helpful discussions.

\section{${ }_{165}$ Notes and references}

- Crystal data for compound $22 \mathrm{MeOH} \mathrm{C} \mathrm{C}_{40} \mathrm{H}_{59} \mathrm{~N}_{7} \mathrm{O}_{2}, \mathrm{Mr}=669.94, \mathrm{~T}=$ 120(2) K, Orthorhombic space group Pbca, $a=10.2826(2), b=$ 20.5801(6), $c=35.6410(10) \AA, V=7542.2(3) \AA^{3}, \rho_{\text {calc }}=1.180 \mathrm{Mg} \mathrm{m}^{-3}, \mu$ $=0.074 \mathrm{~mm}^{-1}, \quad Z=8$, reflections collected: 43094, independent 170 reflections: $6648\left(R_{\text {int }}=0.1269\right)$, final $R$ indices $[I>2 \sigma I]: R 1=0.0656$, $w R 2=0.1445, R$ indices (all data) $R 1=0.1318, w R 2=0.1737$.

1. (a) D.E. Gross, F.P. Schmidtchen, W. Antonius, P.A. Gale, V.M. Lynch and J.L. Sessler, Chem. Eur. J., 2008, 14, 7822-7827; (b) J. L. Sessler, D. E. Gross, W.-S. Cho, V. M. Lynch, F. P. Schmidtchen, G. W. Bates, M. E. Light, and P. A. Gale, J. Am. Chem. Soc., 2006, 128, 12281-12288; (c) J. L. Sessler, P. A. Gale, and W. S. Cho, Synthetic Anion Receptor Chemistry; Royal Society of Chemistry: London, 2006; Chapter 5; (d) P.A. Gale, J.L. Sessler and V. Král, Chem. Commun. 1998, 1-8; (e) J.L. Sessler, V. Král and V. Lynch, J. Am. Chem. Soc., 1996, 118, 5140-5141.

2 D.-W. Yoon, D.E. Gross, V.M. Lynch, C.-H. Lee, P.C. Bennett and J.L. Sessler, Chem. Commun. 2009, 1109-1111; J. Yoo, M.-S. Kim, S.-J. Hong, J.L. Sessler and C.-H. Lee, J. Org. Chem. 2009, 74, 10651069; D.-W. Yoon, D.E. Gross, V.M. Lynch, J.L. Sessler, B.P. Hay and C.-H. Lee, Angew. Chem. Int. Ed. 2008, 120, 5116-5120; C.-H. Lee, H. Miyaji, D.-W. Yoon and J.L. Sessler, Chem. Commun. 2008, 24-34; J.L. Sessler, S.K. Kim, D.E. Gross, C.-H. Lee, J.S. Kim and V.M. Lynch, J. Am. Chem. Soc. 2008, 130, 13162-13166; P.K. Panda and C.-H. Lee, J. Org. Chem. 2005, 70, 3148-3156; D.W. Yoon, H.
Lee, J.-S. Lee, H.-K. Na, D.-W. Yoon, H. Miyaji, W.-S. Cho, and J.L. Sessler, J. Org. Chem., 2005, 70, 2067-2074.

3 B. P. Hay and V. S. Bryantsev, Chem. Commun., 2008, 2417-2428; C. Caltagirone and P.A. Gale, Chem. Soc. Rev. 2009, 38, 520-563.

1954 J.E. Moses and A.D. Moorhouse, Chem. Soc. Rev. 2007, 36, 12491262; P. Wu and V.V. Fokin, Aldrichimica Acta 2007, 40, 7-17.

5 Y. Li and A.H. Flood, Angew. Chem. Int. Ed. 2008, 47, 2649-2652; Y. Li and A.H. Flood, J. Am. Chem. Soc. 2008, 130, 12111-12122; Y. Li, M. Pink, J.A. Karty and A.H. Flood, J. Am. Chem. Soc. 2008, 200 130, 17293-17295; A. Kumar and P.S. Pandey, Org. Lett. 2008, 10, 165-168; H. Jumarker, J.M. Lenhardt, D.M. Pharm and S.L. Craig, Angew. Chem. Int. Ed. 2008, 47, 3740-3743; R.M. Meudtner and S. Hecht, Angew. Chem. Int. Ed. 2008, 47, 4926-4930.

6 P.A. Gale, S.E. García-Garrido and J. Garric, Chem. Soc. Rev. 2008, 205 37, 151-190; P. Prados and R. Quesada, Supramol. Chem. 2008, 20, 201-216; P.A. Gale and R. Quesada, Coord. Chem. Rev. 2006, 250, 3219-3244.

7 For an overview of the membrane transport of anionic species see: A.P. Davis, D.N. Sheppard and B.D. Smith. Chem. Soc. Rev. 2007, 36, 348-357. See also: P. A. Gale, M. E. Light, B. McNally, K. Navakhun, K. E. Sliwinski and B. D. Smith, Chem. Commun., 2005, 3773-3775; J. L. Sessler, L. R. Eller, W. S. Cho, S. Nicolaou, A. Aguilar, J. T. Lee, V. M. Lynch and D. J. Magda, Angew. Chem., Int. Ed., 2005, 44, 5989-5992; P. A. Gale, J. Garric, M. E. Light, B. A. 215 McNally and B. D. Smith, Chem. Commun., 2007, 1736-1738; R. I. Sáez Díaz, J. Regourd, P. V. Santacroce, J. T. Davis, D. L. Jakeman and A. Thompson, Chem. Commun., 2007, 2701-2703; P.V. Santacroce, J.T. Davis, M.E. Light, P.A. Gale, J. C. Iglesias-Sánchez, P. Prados and R. Quesada, J. Am. Chem. Soc., 2007, 129, 1886-1887; 220 J.T. Davis, P.A. Gale, O.A. Okunola, P. Prados, J.C. IglesiasSánchez, T. Torroba and R. Quesada, Nature Chem. 2009, DOI: 10.1038/nchem. 178

8 C.C. Tong, R. Quesada, J.L. Sessler and P.A. Gale, Chem. Commun. 2008, 6321-6323.

2259 R. Custelcean, L. H. Delmau, B. A. Moyer, J. L. Sessler, W.-S. Cho, D. E. Gross, G. W. Bates, S. J. Brooks, M. E. Light, and P. A. Gale, Angew. Chem. Int. Ed., 2005, 44, 2537-2542.

10 A.V. Koulov, T.N. Lambert, R. Shukla, M. Jain, J.M. Boon, B.D. Smith, H.Y. Li, D.N. Sheppard, J.B. Joos, J.P. Clare and A.P. Davis, Angew. Chem. Int., Ed. 2003, 42, 4931-4933.

11 B. D. Smith, and T. N. Lambert, Chem. Commun. 2003, 2261-2268. 


\section{Graphical abstract}

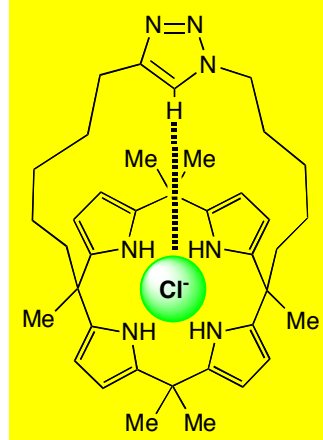

${ }_{240}$ A new 1,2,3-triazole strapped calix[4]pyrrole functions as a chloride transporter in lipid bilayer membranes via both ion-pair transport and anion antiport processes.

\begin{tabular}{|c|c|c|c|c|c|c|c|c|c|}
\hline & & \multicolumn{4}{|c|}{ acetonitrile } & \multicolumn{4}{|c|}{ dichloromethane } \\
\hline host & mode of titration & $\mathrm{K}_{\text {ass }}\left[\mathrm{M}^{-1}\right]$ & $\begin{array}{l}\Delta \mathrm{G}^{\mathrm{o}} / \\
\mathrm{kcal}^{2} \mathrm{~mol}^{-1}\end{array}$ & $\begin{array}{l}\Delta \mathrm{H}^{\mathrm{o}} / \\
\mathrm{kcal} \mathrm{mol}^{-1}\end{array}$ & $\begin{array}{l}\mathrm{T} \Delta \mathrm{S}^{\mathrm{o}} / \\
\mathrm{kcal} \mathrm{mol}^{-1}\end{array}$ & $\mathrm{~K}_{\mathrm{ass}} / \mathrm{M}^{-1}$ & $\begin{array}{l}\Delta \mathrm{G}^{\mathrm{o}} / \\
\mathrm{kcal} \mathrm{mol}^{-1}\end{array}$ & $\begin{array}{l}\Delta \mathrm{H}^{\mathrm{o}} / \\
\mathrm{kcal} \mathrm{mol}^{-1}\end{array}$ & $\begin{array}{l}\mathrm{T} \Delta \mathrm{S}^{\mathrm{o}} / \\
\mathrm{kcal} \mathrm{mol}^{-1}\end{array}$ \\
\hline $1^{1 \mathrm{~b}}$ & & 1.9 e 5 & -7.19 & -10.1 & -3.07 & $4.9 \mathrm{e} 4$ & -6.33 & -10.96 & -4.63 \\
\hline 2 & host $\Rightarrow$ guest & $2.6 \mathrm{e} 6$ & -8.89 & -11.9 & -2.96 & $2.7 \mathrm{e} 6$ & -8.91 & -13.2 & -4.3 \\
\hline 2 & guest $\Rightarrow$ host & $1.3 \mathrm{e} 6$ & -8.47 & -12.0 & -3.52 & \multicolumn{4}{|c|}{ not determined } \\
\hline
\end{tabular}

Table 1: Energetics of tetraethylammonium chloride binding to calixpyrroles $\mathbf{1}$ and $\mathbf{2}$ at $303 \mathrm{~K}$ as determined by isothermal titration calorimetry 